\title{
Designing for Transformative Futures: Creative Practice, Social Change and Climate Emergency
}

\author{
Markéta Dolejšová \\ Aalto University, Espoo, Finland \\ marketa.dolejsova@aalto.fi
}

Ann Light

University of Sussex, Brighton,

United Kingdom

Ann.Light@sussex.ac.uk

Danielle Wilde

University of Southern Denmark,

Kolding, Denmark

wilde@sdu.dk

\author{
Cristina Ampatzidou \\ RMIT Europe, Barcelona, Spain \\ cristina.ampatzidou@rmit.edu.au
}

\author{
Andrea Botero \\ Aalto University, Espoo, Finland \\ andrea.botero@aalto.fi
}

\author{
Lara Houston \\ University of Sussex, Brighton, \\ United Kingdom \\ L.Houston@sussex.ac.uk \\ Jaz Hee-Jeong Choi \\ RMIT, Melbourne, Australia \\ jaz.hee-jeong.choi@rmit.edu.au
}

\author{
Ferran Altarriba Bertran \\ UC Santa Cruz, Santa Cruz, \\ California, USA \\ faltarri@ucsc.edu
}

\author{
Felipe Gonzales Gil \\ ZEMOS98, Seville, Spain \\ felipe@zemos98.org
}

\begin{abstract}
We discuss three cases of transformative creative practice that aim to address large-scale societal issues related to the climate emergency by taking a series of interconnected, small-scale actions. Drawing on our first-hand perspectives, we reflect on how the cases address such issues by proliferating across different social contexts and supporting creative engagements of diverse stakeholders. We offer this empirical reflection at a time of rapid social and ecological change that has affected all life on the planet. Eco-social challenges and structural inequalities caused by shifts in global economic, political and technological power require new approaches and transformative actions to stabilize and restore ecosystems on which life depends. Our research shows that creative practice in art and design has a critical role to play in these processes of transformation. By discussing the opportunities and challenges encountered by our three cases within their transformative efforts and analyzing how they proliferate across diverse scales, we aim to expand the emerging scholarship on the transformative potential of creative practice.
\end{abstract}

\section{CCS CONCEPTS}

- Human-centered computing; • Interaction design; • Empirical studies in interaction design;

Permission to make digital or hard copies of all or part of this work for personal or classroom use is granted without fee provided that copies are not made or distributed for profit or commercial advantage and that copies bear this notice and the full citation on the first page. Copyrights for components of this work owned by others than the author(s) must be honored. Abstracting with credit is permitted. To copy otherwise, or republish, to post on servers or to redistribute to lists, requires prior specific permission and/or a fee. Request permissions from permissions@acm.org.

C\&C '21, June 22, 23, 2021, Virtual Event, Italy

(c) 2021 Copyright held by the owner/author(s). Publication rights licensed to ACM. ACM ISBN 978-1-4503-8376-9/21/06 . \$ \$15.00

https://doi.org/10.1145/3450741.3465242
Ruth Catlow

Furtherfield, London, United Kingdom ruth.catlow@furtherfield.org

\section{KEYWORDS}

Creative practice, Climate emergency, Transformation, Social change

\section{ACM Reference Format:}

Markéta Dolejšová, Cristina Ampatzidou, Lara Houston, Ann Light, Andrea Botero, Jaz Hee-Jeong Choi, Danielle Wilde, Hilary Davis, Ferran Altarriba Bertran, Felipe Gonzales Gil, and Ruth Catlow. 2021. Designing for Transformative Futures: Creative Practice, Social Change and Climate Emergency. In Creativity and Cognition (C\&C '21), fune 22, 23, 2021, Virtual Event, Italy. ACM, New York, NY, USA, 9 pages. https://doi.org/10.1145/3450741.3465242

\section{INTRODUCTION}

The scale of global challenges has become urgent and apparent, affecting all creatures living on this planet. New approaches and transformative actions that stabilize and restore social and ecological systems are critically needed [31]. Increasingly, researchers are pointing to the need for a wider rethink of humanity's impacts on the earth as a whole [7, 12]. However, the pathways towards necessary changes in practices, lifestyles, productive means and political systems are highly contested and intrinsically interdependent. Eco-social mitigation and adaptation require integrative approaches to transform how we live together on the planet, which in turn depend on our cultures, value systems and worldviews [64]. We argue that creative practice in art and design has a critical role to play in these processes of transformation. While design and other forms of making contribute to social and ecological unsustainability [46], they can also play a pivotal role in bringing us towards more positive, sustainable futures. Creative practitioners and researchers have long experimented with diverse methodologies, theories and approaches to support transformative social action; showing that art and design are potent in provoking situations that bring together stakeholders in imaginative, reflective exchange 
$[4,13,21,28,32,34,36,43,49,56,57]$. This process of stimulating transformative thinking and action is fundamental to the kind of shifts in culture that are needed. Creative practitioners are addressing unsustainability, recognizing that it infuses many different domains. This has resulted in diverse creative expressions, from immersive installations urging publics and policymakers to back post-fossil projects [19], to projects enacting a change towards more equal and just social systems [1], to developing new world-views that imagine how we might live well with other species through interconnected existence [9]. An emerging challenge in transformative creative practice today concerns how new practices can proliferate in ways that link scales of operation (e.g. from the local to the global) while being purposeful in making change. This paper explores how three creative projects reach from situated practice to societal change: 1) the Hologram social technologies for peer-topeer health, 2) the Commonspoly game and community round the topic of commoning, and 3) the Feeding Food Futures practice and network for sustainable food transitions. All three projects work across eco-social concerns (dealing with interrelated domains of ecological and social sustainability and acknowledging that climate and ecological sustainability goals will only be attained by addressing social sustainability issues [52]). Each operates within a distinct area of creative, participatory practice: socially oriented art (Hologram), cultural mediation (Commonspoly) and experimental design research (Feeding Food Futures), to foster social change across particular domains of everyday life: health and wellbeing; commoning and governance; food systems and practices - by prototyping more sustainable and just models. Each is structurally interesting in how it scales.

Informed by the concept of scaling out from transition theories $[29,39,41]$ we reflect on how the projects have been designed to proliferate across different social contexts, and support creative engagements with societal challenges. To do this, we critically engage with the scalar relationships and tensions involved in transformative creative practice. We first discuss emerging research on the potential of creative practice to foster sustainable transformation. We then introduce the background of our three cases, their engagement and proliferation strategies, and outcomes so far. Our reporting is informed by our first-hand perspectives as researchers and self-reflective creative practitioners. We aim to provide three insights of relevance to the $\mathrm{C} \& \mathrm{C}$ community into the transformative potential of creative practice: 1) how participatory creative practice can enable a shift from the design of universalizing solutions to the nurturing of stakeholders capacities and relations, 2) how novel dissemination processes for participatory creative practice can function through a nuancing of the concept of 'scaling out', and 3) how creative practice can contribute to new understandings of eco-social transformation.

\section{TRANSFORMATIVE POTENTIAL OF CREATIVE PRACTICE}

Emerging research [21, 27, 32, 34, 36, 43] shows that creative practice in art and design can help us achieve transformative change, by bringing an experiential quality to sustainability projects and stimulating collective reflections and imaginaries of preferable futures. However, this transformative potential has been underutilized and there is untapped knowledge about social change from the arts that can inform social shifts towards resilient living [32, 34]. Sustainability sciences often overlook the value of involving people directly in envisioning conditions for change, re-imagining futures and working towards them. Imaginaries of future situations can help people grasp how changes proposed within eco-social mitigation measures may affect their own and collective lives [21, 24, 44, 53], yet science tends to focus on the material changes needed. Speaking from the context of art and artistic research, Maggs \& Robinson [36] propose that public engagement on sustainability be explored through the lens of aesthetics; as a question of experience, affect, creativity and self-reflection. Artists can produce knowledge that goes beyond rational and physical phenomena to uncover emotional, subjective and experiential insights that lead to a greater understanding of barriers to social change [27, 43, 57].

In design research, creative approaches to inspire social change have long involved participatory design $[4,13,30,47,56]$, transition design [28], critical speculative design [3, 37, 48, 59] and more. For example, the Collaborative Future-Making platform merges co-design and imagination in its anticipatory projects aimed at transformative goals [22]. Much of this work places a focus on locally-situated social innovation that originates within concerned communities, starting from attention to local details, but aiming to inspire long-term, 'ontological' change [15]. In their framework for transformative practice, Hummels et al. [26] highlight that when working towards transformative change, a first-hand perspective is needed: those aiming to foster a change need to engage with, live, feel, embody and 'become' the change on their own. However, while the change may happen at individual or community level, the impact must reach beyond those directly involved to make a significant contribution improving broader social and ecological conditions. This scalar tension underpins our insights here.

In creative practice, there is a strategy of small-scale activity and lateral proliferation across diverse personal, local, social and temporal contexts $([6,33])$. This bears similarities to the conception of scaling out, discussed in transition theories [29, 39, 41]. Scaling out involves the proliferation of an intervention through its iterative, situated duplication in different sites [41]. It stands in inherent opposition to the strategy of scaling up, which follows a commercial-economic expansionist dogma of 'growth at any cost', celebrates centralization, and is thus deeply embedded in many least sustainable industrial practices. Definitions of scaling up and out share the notions of seeking to grow and have greater impact [39], yet they aim to generate different forms of value. Scaling out aims to build capacities that can proliferate across social contexts over time and be changed by the people involved, rather than building fixed products and solutions for generalized, or undifferentiated consumers [29]. It is unsurprising that arts projects tend to favor scaling out, since proliferation allows for local appropriation and a more creative response. The three projects we discuss here take a local focus but experiment with novel and interesting proliferation strategies to expand towards their transformative goals. They address large-scale problems through an ongoing series of interconnected, small-scale actions that are designed to support collaboration and network building. We unpack the projects and their strategies in detail, considering these mechanisms to be of generalizable interest to the $\mathrm{C} \& \mathrm{C}$ community. 

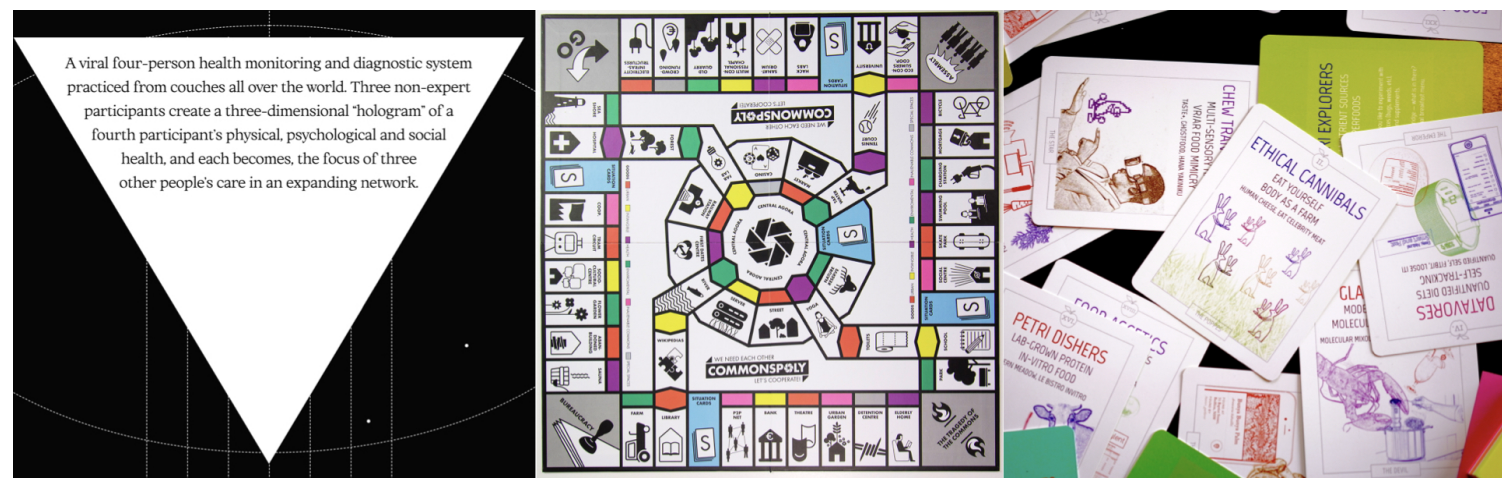

Figure 1: Illustrative images for our three cases: the Hologram system for non-expert healthcare; the Commonspoly game board; FFF's experimental food design prop. Detailed visual documentation of the cases is available at https://creatures-eu.org/

\section{TRANSFORMATIVE CREATIVE PRACTICE: THREE CASES}

The three cases explored here (Figure 1) have been recently brought together by the research project CreaTures (Creative Practices for Transformative Futures; https://creatures-eu.org/). Prior to this, they developed independently. The co-authors of this paper have varied professional relationships with the projects: some have been involved as practitioners directly designing the creative works and engagement activities; others had the role of participant observers. For the analysis here, we used heterogeneous materials collected by all co-authors, experimenting with "inventive methods" [35] drawn from the social sciences. For the Hologram, data used included: 7 interviews with the project's initiators, auto-ethnographic journal entries from 2 Hologram courses, 6 interviews with course facilitators; for Commonspoly: 3 interviews with the project's initiators, participation notes from 4 gaming sessions, and visual outcomes of a mapping session sketching relational networks of individuals and communities that emerged from the game's deployment [10]; for FFF: 3 interviews with project initiators, auto-ethnographic notes and visual documentation from 2 FFF workshops, a set of 9 survey responses gathered from participants. Drawing on these materials, we crafted textual narratives for each case, summarizing insights that were analysed using a reflexive thematic analysis approach [8] where all co-authors were part of a generative process of meaningmaking. For the sake of consistency, the cases are reported in the third person.

\subsection{The Hologram}

3.1.1 Background. The Hologram: Collective Health as a Really Beautiful Artwork (https://thehologram.xyz/) is a strand of work led by artist Cassie Thornton, dedicated to developing social technologies for peer-to-peer healthcare. At the center of the project is a simple structure: a person - known as 'the hologram' - invites three friends or acquaintances (known as 'the triangle') to meet on a regular basis to discuss their physical, emotional and social health. The project as a whole has produced a protocol that individual holograms can use to facilitate these meetings (The Hologram is capitalized when referring to the project; in lower case when referring to individual practitioners). Thornton first encountered this structure in 2016 whilst visiting the Thessaloniki Workers' Clinic (set up in response to Greece's financial and refugee crises) where people are treated by a team of three practitioners, producing a three-dimensional or 'holographic' view of their physical, social and psychological life [58]. In 2020, Thornton embarked on a residency with the non-profit arts organization Furtherfield, working with artists Ruth Catlow and youth worker Lita Wallis, where she began to experiment with the possibilities of the hologram structure outside of a clinical setting. Out of this came an ongoing series of ten-week courses that have acted as experimental sites to stabilize a protocol for the practice of 'social holography' and as dissemination channels for newcomers to learn the practice [58]. To date, three courses have been completed, with around 25 participants each. The following auto-ethnographic excerpt gives an overview of the five steps in a hologram meeting.

'The sun is setting when I log into the first Hologram session. As the Zoom window flutters open, I hear the sound of pop music as I watch 27 other faces pop up on-screen. After an introductions round, it's time for a demonstration. A course facilitator becomes the hologram, three volunteers take the role of her triangle. 1] Each group member starts with the 'stuck dance,' making a shape with their body, to share corporeal impressions. 2] The hologram 'marks the task' that she'd like to address today - she's at a transition point in her life and wants to be surrounded by positive feelings. 3] The triangle gently ask her clarifying questions, using "we" instead of "I", thereby creating a powerful collectivizing effect. In answering their questions, the hologram allows herself to become vulnerable, even in front of this unknown audience. 4] The triangle members are invited to reflect. One tells the hologram how privileged he felt to take part in the meeting. In that moment any trace of shame stemming from vulnerability is transmuted into radical acceptance. I feel my heart swell. 5] The triangle provides feedback to the hologram in the form of patterns, wishes or provocations.' (researcher's notes, 2020)

3.1.2 Transformative Goals. Central to the Hologram project is an understanding of health that moves beyond the idea of (dys)functional bodies. Health is understood in relational terms, as selves and bodies take shape in relation to the prevailing conditions of social, economic and political life - echoing research showing that people are more able to maintain good health in more equal 
societies that feature higher degrees of trust [50]. The Hologram therefore responds to societal-scale challenges and seeks to make change at that level, as Thornton explains: "at its broadest and most ambitious scale the Hologram is intended as an open-source, peer-to-peer, viral social technology for de-habituating humans from capitalism" [58]. Since capitalism is a social phenomenon that "deeply influences how we relate to one another, how we interact, how we imagine ourselves and one another, even how we talk and feel" [58] the Hologram, as a social technology, intends to change these "cultures of financialization" [18] by giving people experiences of radical acceptance, and a structure that they can use to prioritize self-care with trusted others. Two participants (who were later trained as facilitators) detailed the skills they had learned from the course: including patience, courage, listening, questioning and emotional stamina - the experience "of not needing to have the answer and feeling confident enough to try something, knowing it might not work out" (interview, 2021). They felt the course boosted participants' sociological imagination: "your capacity to imagine yourself as part of a whole and imagine how that whole impacts you" (interv., 2021). Hologram practitioners are invited to share these insights (and the inevitable challenges that also arise) in a dedicated community of practice - convened via a text chat app and online monthly meetings. The assumption at the heart of the project is that these intimate transformations will aggregate in ways that change wider capitalist relations towards structures that are more sustainable for humans and earth systems. The concept of care is central to the Hologram: people need caring relations in their lives, but they also need to be treated with care when interfacing with wider systems (care is conceived throughout this text as fundamental respect for all living entities - following emergent work bridging feminist, materialist scholarship with concerns for environmental phenomena [51]). The Hologram aims to create a transformative program of un-learning to help people undo internalized norms about who deserves care, and gives them tools to remake their own conditions.

3.1.3 Scaling out the Hologram Practice. Given the project's huge ambition, Thornton has given thought to how the project can scale, and has embedded a viral scaling mechanism inside the practice itself. Simply put, when a new triangle is formed, the hologram is tasked with supporting her triangle members to set up new hologram groups for themselves. This is not merely a dissemination mechanism but is central to the relations of care. As Catlow explains: "as a hologram you are very invested in the health of your triangle, you understand that it's equally important to take responsibility for the health of your triangle members by helping them to learn how to be a hologram themselves" (interv., 2020). This central convention allows for reciprocation between the triangle members (who are providing care) and the hologram (who is receiving it). However, it also avoids any transactional requirement that the exchange be equalized. Instead, relations of care radiate outwards as holograms invite triangles, who become holograms, who invite triangles. In designing this viral peer-to-peer form, Thornton was inspired by the Black Panther Party's sharing of acupuncture techniques within their activist movement [38]. The project team are continuing to disseminate the practice via this viral scaling mechanism, the aforementioned courses, and The Hologram book [58].
They are currently inviting groups from beyond the art world (such as healthcare workers) to join the project and to actively mutate the practice. Thornton hopes to exit project in 2023 and is actively opening up stewardship to curators, co-facilitators and others in the community of practice.

\subsection{Commonspoly}

'As I open the box and take out the game board, I take the time to look carefully at all the spaces laid out. I know that this game is a criticism of Monopoly, so I immediately look for familiar references. I make unexpected discoveries, such as the hack lab and the multi-confessional chapel and I appreciate the diversity in the character descriptions. As I lay down the rest of the game tokens, I instinctively wonder: Where is the money?' (researcher's notes)

3.2.1 Background. Commonspoly (https://commonspoly.cc/) is a non-profit, open source board game initiated by the Spanish cultural cooperative ZEMOS98, designed to stimulate a collaborative, commons-based approach to the use of public resources and question the violent model of neoliberal privatization. The first Commonspoly version was developed in 2015 during a cultural festival in Seville: a working group of 13 decided to hack the popular board game Monopoly [40] whose design principles prescribe land monopolization, rent extraction and driving competing players to bankruptcy as a win strategy. In contrast, Commonspoly invites players to collectively convert private spaces on the game board to public, and eventually into common holdings. Commonspoly is typically played in public game sessions at cultural events, but the game can also be purchased or downloaded as print-ready files and played privately. Upon request, ZEMOS98 provides editable game files to encourage collaborative game development, which is further supported through co-creative events with diverse local communities. So far, the game has reached people in 23 countries, been released in five iterations, and exists in four languages.

3.2.2 Transformative Goals. The game's design principles draw on insights from commoning practices [5] and encourage players to pool their resources and act collectively against 'looming speculators' - nefarious game characters advocating privatization, often played by the game facilitators. ZEMOS98 co-founder adds: "In this game, as in reality, you're in a race against time and need all the help you can get to bring about change" (interv., 2020). The game thus aims to bring players together to negotiate and imagine various commoning strategies and engage in critical discussion. As such, Commonspoly forms part of a growing corpus of critical games $[11,16]$ that encourage critical thinking about hegemonic ideas and unsustainable practices through principles embedded in the game design. The Commonspoly project works towards social change through two means: 1) the collective development, distribution and appropriation of the game across diverse local, social contexts; 2) the individual gameplays that bring together stakeholders interested in commons into a critical discussion. Through these processes, the project has attracted a variety of stakeholders and scaled into a distributed community network focused on the topic of commons.

3.2.3 Scaling out the Commonspoly Practice. The growth of the Commonspoly network has brought about a greater diversity of 
inputs for the game, but also several practical concerns. One of the key challenges for ZEMOS98 is to manage tensions emerging from the collective game development and Intellectual Property (IP). Defining the exact scope of contributions by all authors who supported the iterative game progress and including them in every new game version release is impossible. Managing contributors' expectations and facilitating negotiation about various game changes became too resource-demanding for a small collective like ZEMOS98 that currently has 5 members and is supported mostly by arts funding. To address the issue, ZEMOS98 embraced the concept of 'forking' that originates in the free software movement [54] and involves individual naming of all different versions coming from one original source to satisfy contributors' distinct needs. Each new Commonspoly fork is thus named and described by its author and licensed under the Peer Production License that enables any non-profit entity to use and adapt the game for non-commercial use. ZEMOS98 is only listed as author of the first fork, for which it is accountable; thus leaving an open space for a collective Commonspoly authorship to flourish. Many fork authors have shared their versions: For instance, a Brazilian teacher adapted the game to the local context for her students; a UK-based Esperanto expert made a game translation. The collective game development is an ongoing process, and - similar to the free software movement the 'success' of this approach is likely to emerge over time, as the collective authorship of the game unfolds.

Another issue in scaling out Commonspoly is distribution: finding appropriate channels and resources to distribute the physical game widely, across diverse geographical areas and communities, has proved difficult. Staying true to their commitment to commoning values, ZEMOS98 deliberately avoids large suppliers with monopolistic practices such as Amazon. Until recently, the collective would store the full stock of game copies and dispatch them on an individual basis, which was costly and inefficient. To scale out their distribution system, ZEMOS98 has recently started leveraging the Commonspoly community to establish a network of 'Ambassadors': individuals and small bookshops that manage the sales and distribution of small game stocks locally, acting as Commonspoly advocates as well as gameplays facilitators. 10 bookstores around Spain have been successfully secured and the network is envisioned to expand internationally. To address how lack of resources hinders their efforts in Commonspoly development, ZEMOS98 has also worked on sustaining collaborations and relations with like-minded cultural institutions. Through their long-standing collaboration with the European Cultural Foundation (ECF), the collective has been able to produce more physical game copies, and expand their community of practice by accessing ECF's audiences. The decision to include institutions in their - decidedly grassroots - processes was not straightforward for ZEMOS98: "By having access to larger institutional bodies, we can sustain our connections with smaller actors and individuals. But that's related to our survival rather than our desire. Ideally, we would skip larger bodies...but till now they have been an essential resource for" (pers comm., 2020). Nevertheless, the aim is to keep these institutional collaborations truthful to the commoning values and maintain a mutually beneficial relationship: "ECF provides financial support, but also knowledge; we provide our knowledge and experience in return. We don't feel merely funded, but rather like nurturing a relationship that follows a shared goal: fostering solidarity and strengthening democracy." (pers. comm., 2020). For ZEMOS98, Commonspoly is not a product but a resource. Rather than promoting the game to sell more copies, Commonspoly is designed to help educate people about commoning; its methods of distribution are designed with the same values as the game board. Rather than developing a network for efficient distribution, ZEMOS98 nurtures an international network of relations that includes local Commonspoly players, Ambassadors, and cultural institutions. By dissolving their authorship and 'forking' it widely, ZEMOS98 enables a pluralistic game development, paying attention to local contexts.

\subsection{Feeding Food Futures}

'At our foraging walk around the workshop venue, we notice that local dining options consist of either expensive hotel restaurants or fast-food chains. Acknowledging our privilege of 'luxury of choice', we take lunch at a pizza joint. While eating pizza and sipping soda from gigantic plastic cups, we talk about unequal socio-economic access to 'good' (healthy, sustainable) food-tech products designed for 'good' food practices. As food-tech designers, we need to pay attention to diverse socio-economic sensitivities in food cultures.' (FFF practitioner, auto-ethnographic notes).

3.3.1 Background. Feeding Food Futures (FFF; https://foodfutures. group/) is a long-term experimental design research project aiming to support critical inquiry into emerging food-technology innovation and nurture imaginaries towards resilient food futures. The project was co-founded in 2019 by four design researchers working at four different universities across the world. It encompasses an ongoing series of co-creative events including workshops, future enactments and performative tastings that enable critical exchange among food-oriented researchers, designers and practitioners. The events are situated primarily at academic conferences where key stakeholders in food-tech design and research usually meet (e.g. DIS, CHI, C\&C, CHIPlay). Academia is FFF's 'natural habitat', from where it sprouts, and from where it aims to start making a change: "Supporting a change in food-tech scholarship - which is inevitably connected to the food-tech industry - is the first step for us to help foster sustainable change in wider food systems" (interview with FFF co-founder, 2020). Through the ongoing events series, FFF has proliferated into a globally distributed network of contributors interested in experimenting with diverse co-creative means to support sustainable food transitions.

3.3.2 Transformative Goals. FFF critically reflects on the role of food-tech innovation in addressing systemic challenges such as food insecurity and unsustainability, which have been identified as outcomes of climate change [63]. Food-tech designers are proposing a variety of techno-solutions for 'better', more sustainable food practices - from smart kitchenware to digital farming platforms. Many of these proposals are problematic in their impacts on food cultures, extending socio-economic inequalities in global food markets and causing negative changes to social food traditions [14]. Concerned with what has been identified as a lack of critical reflection in existing food-tech design and research [2], FFF was initiated to gather critical voices and foster new experimental collaborations. The project leverages the methods of experimental food design research 
[14] grounded in embodied co-creation [23, 62] using food both as a research object and a sensory-rich bio-design material. In FFF, food and food practices are considered as relatable everyday-life elements that happen at the scale of the body - the scale at which people operate, think and easily imagine. Thus, designing with food enables consideration of issues that are global in scope, yet intensely personal in their unfolding. Starting from this methodological angle, each FFF event is different: taking place in a local venue, engaging different groups of participants in activities including co-designing future food scenarios and prototypes, conducting foraging walks, and working with food design props such as the Food Tarot cards [17]. While different in their formal scope, the events are designed with the same goal in mind: to bring diverse food stakeholders into a critical human-food-tech exchange that results in co-creative outcomes to be disseminated to wider publics. Among examples from past events are the open-access Human-Food Interaction Zine with recommendations for equitable food-tech design and research [25] or the More-than-Human Food Futures Cookbook with experimental recipes for resilient food system processes [42]. Detailed description and analysis of 6 FFF events are available in $[14,61]$.

3.3.3 Scaling out the FFF Practice. FFF workshops have shown there is interest among scholars and designers in addressing foodtech innovation issues through critical, experimental means and a lack of venues for long-term exploring. This gap has motivated the ongoing proliferation of FFF into a decentralized, globally distributed network of collaborators, who are invited to propose new food design research activities and develop them autonomously, leveraging the network as a resource of knowledge and opportunities for collaboration. These efforts in scaling out a food community network are envisaged to contribute to societal level (food system) change. Reaching from situated events into a distributed network for food system transitions, this work could be a step towards larger social impact. Yet, distributing design research practice in this way can be challenging: "We have been encouraging network contributors to co-organize events with us, engage in joint co-authoring of publications, and to propose new events on their own. The oversight of network activities still remains largely with us, though [...]. Network contributors have engaged actively but not yet autonomously" (FFF co-founder, interv., 2020). A number of factors contribute: FFF contributors may have diverse motivations and commitments; academia's traditional authorship model may be a constraining factor as well. The pressures of the job keep many academics tightly focused on activities recognized by their institutions as having value, and authorship can be a contested process - in academia, shared collective co-authorship that decenters the role of 'lead' author is not well supported. At the heart of FFF's journey in becoming a diverse, transformative network is thus the challenge of transcending the boundaries of academia while still being a productive part of it. The project makes an ongoing effort to bring new critical voices into the academic food design research and nurture its post-disciplinary flourishing. To learn more and support the network, new open-ended FFF activities have been planned including seminars led by network members, a co-organized workshop at an artistic research festival, a free-access workshop at a design research conference, and an online reading group. These activities are envisioned as less formal entry points from which network members might take the initiative and propose new - perhaps unexpected, surprising - forms of collaboration. Nurturing such 'hybrid' food design research spaces on the boundary of the academic realm can be a potent strategy for co-creative design research initiatives: they can provide an opportunity for knowledge exchange that may be beneficial for long-term work of both academic and non-academic participants. Through these actions, FFF aims to foster rich post-disciplinary ground from which buds of better futures - in food practices as well as in related research efforts - might sprout.

\section{CRAFTING TRANSFORMATIVE CHANGE: CREATIVE PRACTICE PROLIFERATING ACROSS SCALES}

We have introduced three empirical cases where creative practice opens up new terrains for thinking and prototyping alternate visions for more socially and ecologically sustainable ways of life. The projects use creative approaches drawn from art, cultural mediation, and experimental design research to explore transformative ecosocial change in various everyday-life contexts. While their basic structures are specific to a small number of people and a particular context, they aspire to simultaneously engender change in global systems through various forms of proliferating. The Hologram enacts healthcare that works towards a speculative post-capitalist future where peer cooperation is an essential value. It supports people's personal transformation within small groups through a functional 'self-replicating' system based on mutualistic care rather than normative transactional relations. The Commonspoly game is a playful, discursive artifact and process designed to stimulate a collaborative, commons-based approach to the use of resources. As a commoning artifact itself, Commonspoly considers players as game co-developers, leveraging their diverse local and personal knowledges both in the game development and in distribution. The FFF project nurtures experimental approaches to academic food-tech design and research, challenging the lack of critical scholarship in the area. By functioning as a long-term network for decentralized collaboration, FFF's goal is to support a post-disciplinary change in food-tech academia; a small but important step in contributing towards sustainable transitions of food systems and practices. In these three distinct but carefully designed methods for the spread of transformative ideas, we see the artistry, not merely of new speculations, but of the cunning manipulation of the health, ownership, and food systems being challenged. Each project is designed for spreading within its system, as well as for addressing its core theme. By looking at these reproductive mechanisms, we can learn something generalizable about the structure and agency of change and the nature of tackling systems from within, as well as the more idiosyncratic goals of each project.

\subsection{Shifting Modes: from Knowledge of Problems to the Nurturing of Relations}

The three projects serve as a common ground for open-ended engagements among diverse stakeholders who are interested in working together towards social change. They aim to empower civil and civic society actors to be collaborative agents of change by 
following co-creative approaches to capacity building from participatory design $[4,13,30]$, embodied design experiments [14, 23, 62], commoning practices [5] and alternative techniques for social and health care $[38,58]$. The participatory structures in the heart of all three projects - the setting up of triangles of care in the Hologram; the collaborative strategies that Commonspoly players need to embrace; the food scenarios co-designed at FFF events - contribute towards networks of relation that help each project to disseminate their activities more widely and invite new people across new sites to become active part of the infrastructure. Rather than aiming to change personal behaviors by imposing individualistic solutions based on top-down agendas, the projects build capacities, nurture relations, and provide resources that can be adapted to suit stakeholders' specific - local, personal, research-oriented - needs, while keeping the needs of the overall system in view. This marks an important shift from older, knowledge-based models of creative practice and sustainability, where creative works are used to communicate (often scientific) findings to wider audiences in order to encourage behavior change (as discussed at length e.g. in [36]). As Light et al. [34] explain, creative practice can, instead, "allow people to explode systems, expand cause-effect relations, and raise consequences in a manageable way. At its most effective, [cr. practice] inspires people to make changes for themselves and (..) inspire others to follow". Our projects show that creative art and design practice can indeed play such a role and engage people actively with their interconnectedness and interdependence. By staying open to participants' inputs, the projects and their practices nurture (and scale-out) new relations.

\subsection{Proliferating Relations by 'scaling Out'}

With transformative ambitions, the three projects remain perpetually unfolding: experimental processes in progress, where spread and mutation are designed into the form of the work. The projects scale their practice across local and social contexts by leveraging networks of triangles and holograms, game players and ambassadors, and design/research co-authors who enact the practice - or mutations thereof - in their distinct, personally-situated contexts. These networks are the focus of considerable effort: the relational aspects are part of what is being modelled and replicated. To spread their practice in this lateral way, the 'monopoly' over the projects' authorship is purposely dissolved and the projects' processes and structures are open to be renegotiated. Openness to (re)negotiation of community values based on emerging insights is a defining element of scaling out processes [29] standing in direct contrast to the notion of scaling up, which furthers the idea of progress and growth, without changing organizational structures and framings. Although network contributors in the three projects are encouraged to propose their own project iterations, spin-offs, forks or entirely new activities, there is trust that values stay true and in line with the networks' goals. The projects are thus being gradually transformed in the direction of a large-scale aim - not by performing a series of linear steps towards a concrete and definable goal, but by iteratively performing small changes and actively accumulating, nurturing, and responding to diverse situated knowledges. Haraway [20] articulates situated knowledges as a crucial counter to the false 'objectivity' of economic and policy perspectives based on the top-down managerial models of socio-technicality and we see this countering here. As Haraway and others [55, 60] observe, efforts to enact alternative values are not trivial, and there are risks and uncertainties inherent to how such efforts unfold. While purposefully bypassing mainstream distribution chains like Amazon, ZEMOS98 struggles with securing sufficient resources to facilitate the game distribution across alternative channels, such as independent bookstores. The 'autonomous sprouting' of the FFF network, which hinges on proactive behavior of network contributors and collective authorship, can be challenging to achieve within the academic context. The Hologram recognizes that its culture is shaped by the Anglo-American art world, and encounters productive frictions as it experiments with new ways to engage diverse groups in learning the practice and intervening into the culture of the project itself. However, what the mechanisms in the three projects point to is a different structural relationship with change, which is not merely invested in proposing new ideas, but new ways of encountering the domain in which they are performing. For instance, as noted, IP is a particular theme for Commonspoly and it uses open source approaches to sharing and in its Ambassador program. It is a network encounter with form following function. Each project is a comment on the domain as much as functioning as a set of specific activities within the domain.

\subsection{Challenges of Designing for Relational Transformative Structures}

Supporting long-term, relational, open-ended engagements and knowledge exchange among interested groups as a form of designing for change can be difficult to articulate at the level of policymaking and evaluation for impact, which often require quantitatively measurable evidence. As Light et al. [34] observe, while sustainable change requires shifts in knowing, feeling and being, the 'rational actor' myth has led to emphasis on information at the expense of work on collective values and more collaborative, creative approaches to transformation. In contrast to normative, universalizing solutions where value can be measured through, for example, the number of copies sold and apps downloaded, relational transformative work requires considerable effort and time to prove its 'success'. This may sound counter-intuitive when global social change is urgently needed. However, as we have addressed throughout this paper, the urgency of climate crisis requires both large-scale global action and transformative practices at smaller, interpersonal scales. Personal connections and a relational sense of peer investment are necessary ingredients of any recipe for eco-social transformation [45]. The projects we introduced trouble spatial metaphors and make themselves hard to classify. Yet, through scaling out, they provide much needed space for local actors to re-iterate and re-form specific practices according to their own needs and desires, rather than imposing a centralized, topdown control. The support and networking structures that link their disparate offshoots become responsive to local conditions as they grow. These kinds of transformative creative practice demand new, more diverse epistemological approaches to recognize their value and foster further proliferation. Policy-making and evaluation strategies for their impact must adapt to, if not welcome, the opportunity to address this urgent need. Priorities need to be adjusted to 
foster transformation in fundamental values and systems instead of focusing on conspicuous, easily measurable attributes of individual actions. As our cases demonstrated, meaningful success is not just about recycling more food containers or spending less on healthcare, but questioning the system that enables the continued uses of plastic packaging, or preventing the establishment of universal healthcare.

\section{CONCLUSION}

Living and designing in uncertain times requires us to work with resistance to existing structures and offer hope by proposing new ones. In this paper, we discussed some ongoing strategies and tactics used in creative practice to foster transformations towards more resilient and equitable living. Through our empirical cases, we aimed to demonstrate the ability of creative practice to work across scales and facilitate sustained engagements of diverse stakeholders with contemporary societal challenges. Given the global scale of the challenges addressed, the class of practice identified here is a valuable addition to the many more change-focused, solution-oriented initiatives intended to elicit sustainable lifestyles. Instead of following this path, the practices here continue to develop the capacity to leverage experimental, open-ended processes of co-creative thinking and acting through their own transformations, thus helping to plant seeds for imaginative exchange, new intersectional coalitions, learning and action. In offering this analysis, we hope to further understanding of these alternative practices, so that they are recognized, valued, and supported at all levels of transformation.

\section{ACKNOWLEDGMENTS}

This project has received funding from the European Union's Horizon 2020 research and innovation programme under grant agreement No 870759. The content presented in this document represents the views of the authors, and the European Commission has no liability in respect of the content.

\section{REFERENCES}

[1] Shana Agid. 2018. 'Dismantle, change, build': Designing abolition at the intersections of local, large-scale, and imagined infrastructures. Design Studies 59: 95-116.

[2] Ferran Altarriba Bertran*, Samvid Jhaveri, Rosa Lutz, Katherine Isbister and Danielle Wilde*. 2019. Making Sense of Human-Food Interaction. In CHI Conference on Human Factors in Computing Systems Proceedings May 4-9, 2019, Glasgow, Scotland UK. ACM, New York, NY, USA. *co-first authors

[3] Heidi R. Biggs and Audrey Desjardins. 2020. High Water Pants: Designing Embodied Environmental Speculation. In Proceedings of the $2020 \mathrm{CHI}$ Conference on Human Factors in Computing Systems (CHI '20). Association for Computing Machinery, New York, NY, USA, 1-13.

[4] Erling Björgvinsson, Pelle Ehn, and Per-Anders Hillgren. 2012. Agonistic participatory design: working with marginalised social movements. CoDesign $8,2-3$ : 127-144.

[5] David Bollier and Silke Helfrich. 2015. Patterns of commoning. Commons Strategy Group and Off the Common Press.

[6] Andrea Botero, Ann Light, Lone Malmborg, Sanna Marttila, Mariana Salgado, and Joanna Saad-Sulonen. 2016. Becoming Smart Citizens: How Replicable Ideas Jump. In Workshop at the Design and the City conference, Amsterdam. Retrieved February 17, 2021 from https://designandthecity.eu/programme/workshop/becomingsmart-citizens-how-replicable-ideas-jump.

[7] Corey J. A. Bradshaw, Paul R. Ehrlich, Andrew Beattie, Gerardo Ceballos, Eileen Crist, et al. 2021. Underestimating the Challenges of Avoiding a Ghastly Future. Frontiers in Conservation Science.

[8] Virginia Braun and Victoria Clarke. 2020. One size fits all? What counts as quality practice in (reflexive) thematic analysis?. Qualitative research in psychology, 1-25.

[9] Rachel E. Clarke. 2020. Ministry of Multispecies Communications. In Companion Publication of the 2020 ACM Designing Interactive Systems Conference, 441-444.
[10] Commonspoly network mapping. 2021. Retrieved April 28, 2021 from https://creatures-eu.org/wp-content/uploads/2021/04/201217-TheCommonspoly-network.pdf.

[11] Francesco Crocco. 2011. Critical gaming pedagogy. The Radical Teacher, 91: 26-41.

[12] Partha Dasgupta. 2021. The Economics of Biodiversity: The Dasgupta Review. Retrieved 26 April, 2021 from: https://www.gov.uk/government/publications/ final-report-the-economics-of-biodiversity-the-dasgupta-review.

[13] Carl DiSalvo, Illah Nourbakhsh, David Holstius, Ayça Akin, and Marti Louw. 2008. The Neighborhood Networks project: a case study of critical engagement and creative expression through participatory design. In Proceedings of the tenth anniversary conference on participatory design, 41-50.

[14] Markéta Dolejšová*, Danielle Wilde*, Ferran Altarriba Bertran, and Hilary Davis. 2020. Disrupting (More-than-) Human-Food Interaction: Experimental Design, Tangibles and Food-Tech Futures. In Proceedings of the 2020 ACM Designing Interactive Systems Conference, 993-1004. *co-first authors

[15] Arturo Escobar. 2018. Designs for the pluriverse: Radical interdependence, autonomy, and the making of worlds. Duke University Press.

[16] Mary Flanagan. 2009. Critical Play: Radical Game Design . Cambridge, Mass: MIT Press.

[17] Food Tarot cards. 2021. Retrieved February 17, 2021 from https://foodtarot.tech/

[18] Max Haiven. 2014. Cultures of financialization: Fictitious capital in popular culture and everyday life. Springer.

[19] Maarten A. Hajer and Peter Pelzer. 2018. 2050-An Energetic Odyssey: Understanding "Techniques of Futuring" in the Transition towards Renewable Energy. Energy Research \& Social Science 44: 222-31. https://doi.org/10.1016/j.erss.2018. 01.013.

[20] Donna Haraway. 1988. Situated knowledges: The science question in feminism and the privilege of partial perspective. Feminist studies 14, 3: 575-599.

[21] Mia Hesselgren, Elina Eriksson, Josefin Wangel, and Loove Broms. 2018. Exploring Lost and Found in Future Images of Energy Transitions: Towards a Bridging Practice of Provoking and Affirming Design. In Proceedings of Design Research Society 2018, University of Limerick.

[22] Per-Anders Hillgren, Kristina Lindström, Michael Strange, Richard Topgaard, and Hope Witmer. (eds.). 2020. Glossary: Collaborative Future-Making. Malmö University.

[23] Kristina Höök. 2018. Designing with the body: Somaesthetic interaction design: MIT Press.

[24] Rob Hopkins. 2019. From what is to what if: Unleashing the power of imagination to create the future we want. Chelsea Green Publishing.

[25] Human-Food Interaction Zine. (2019). Retrieved February 18, 2021 from http: //bit.ly/HFIzine

[26] Caroline Hummels, Ambra Trotto, Jeroen Peeters, Pierre Levy, Jorge Alves Lino, and Sietske Klooster. 2019. Design research and innovation framework for transformative practices. In Strategy for change. Glasgow Caledonian University, $52-76$

[27] International Institute for Applied Systems Analysis. 2017. The art of systems analysis. How can artists support transformations to sustainability? Laxenburg. Retrieved February 17, 2021 from http://www.iiasa.ac.at/web/home/about/scarts/ ScienceArt_Brochure_A4_28pages_singlepages_web.pdf

[28] Terry Irwin. 2015. Transition Design: A Proposal for a New Area of Design Practice, Study, and Research. Design and Culture 7(2): 229-46.

[29] Airi Lampinen, Chiara Rossitto, and Christofer Gradin Franzén. 2019. Scaling Out, Scaling Down: Reconsidering growth in grassroots initiatives. In Ethnographies of Collaborative Economies Conference, Edinburgh, Scotland, UK

[30] Christopher A. Le Dantec and Carl DiSalvo. 2013. Infrastructuring and the formation of publics in participatory design. Social Studies of Science 43, 2: 241-264.

[31] Melissa Leach, Kate Raworth, and Johan Rockström. 2013. Between Social and Planetary Boundaries. In ISSC/UNESCO, World Social Science Report 2013: Changing Global Environments. Paris: OECD publishing and UNESCO Publishing, 84-89. https://doi.org/10.1787/9789264203419-en

[32] Ann Light, Deborah Mason, Tom Wakeford, Ruth Wolstenholme, and Sabine Hielscher. 2018. Creative practice and transformations to sustainability: Making and managing culture change. AHRC Connected Communities Projects. Retrieved February 17, 2021 from https://connectedcommunities.org/wpcontent/uploads/2018/08/Creative-Practice-and-Transformations-toSustainability-Making-and-Managing-Culture-Change.pdf

[33] Ann Light and Clodagh Miskelly. 2019. Platforms, scales and networks: meshing a local sustainable sharing economy. Computer Supported Cooperative Work (CSCW) 28, 3: 591-626.

[34] Ann Light, Ruth Wolstenholme, and Ben Twist. 2019. Creative practice and transformations to sustainability - insights from research. SSRP Working Paper No1, Sussex Sustainability Research Programme, Sussex University.

[35] Celia Lury and Nina Wakeford. 2012. Inventive methods: The happening of the social. Routledge.

[36] David Maggs and John Robinson. 2020. Sustainability in an Imaginary World: Art and the Question of Agency. Routledge. 
[37] Luiza Prado de O. Martins. 2014. Privilege and Oppression: Towards a Feminist Speculative Design. In Proceedings of Design Research Society 2014 conference, Umea, Sweden

[38] Eana Meng. 2020. An Introduction: The Black Panther Party and Acupuncture? Retrieved February 17, 2021 from https://www.ofpartandparcel.com/blog-2/anintroduction-the-black-panther-party-and-acupuncture

[39] Joanne Millar and John Connell. 2010. Strategies for scaling out impacts from agricultural systems change: the case of forages and livestock production in Laos. Agriculture and human values 27, 2: 213-225.

[40] Monopoly - Hasbro (1935/2021). Retrieved February 18, 2021 from https:// monopoly.hasbro.com/

[41] Michele-Lee Moore, Darcy Riddell, and Dana Vocisano. 2015. Scaling out, scaling up, scaling deep: strategies of non-profits in advancing systemic social innovation Journal of Corporate Citizenship, 58: 67-84.

[42] More-than-Human Food Futures Cookbook. 2021. Retrieved February 18, 2021 from http://bit.ly/book_anon

[43] Lucy Neal. 2015. Playing for Time: Making Art as if the World Mattered. Oberon Books.

[44] Alexandra Nikoleris, Johannes Stripple, and Paul Tenngart. 2017. Narrating climate futures: shared socioeconomic pathways and literary fiction. Climatic Change 143, 3-4, 307-319.

[45] Karen O’Brien. 2012. Global environmental change II: From adaptation to deliberate transformation. Progress in Human Geography 36, 5: 667-676.

[46] Victor Papanek. 1972. Design for the Real World: Human Ecology and Social Change. London: Thames and Hudson.

[47] Leonardo Parra-Agudelo, Jaz Hee-jeong Choi, and Marcus Foth. 2017. The city as canvas for change: Grassroots organisations' creative playing with Bogota. In Playable Cities. Springer, 189-210.

[48] Sarah Pennington. 2018. Taking Care of Issues of Concern: feminist possibilities and the curation of Speculative and Critical Design. In Proceedings of Design Research Society 2018, University of Limerick.

[49] Laura J. Perovich. 2018. Environmental art: A path to civic progress in a time of policy retreat in the United States. Cogent Arts \& Humanities 5, 1: 1523269.

[50] Kate Pickett and Richard Wilkinson. 2010. The Spirit Level: Why Equality is Better for Everyone. Penguin Books.

[51] Maria Puig de la Bellacasa. 2017. Matters of Care, Speculative Ethics in More Than Human Worlds, University of Minnesota Press, USA.

[52] Jorgen Randers, Johan Rockström, Per Espen Stoknes, Ulrich Golüke, David Collste, and Sarah Cornell. 2018. Transformation is feasible: How to achieve the sustainable development goals within planetary boundaries. A report to the Club of Rome, for its 50 years anniversary, 17.

[53] Paul G. Raven. 2017. Telling tomorrows: science fiction as an energy futures research tool. Energy Research \& Social Science, 31, 164-169.

[54] Gregorio Robles and Jesús M. González-Barahona. 2012. A comprehensive study of software forks: Dates, reasons and outcomes. In IFIP International Conference on Open Source Systems, 1-14. Springer, Berlin, Heidelberg.

[55] Peter Rogers. 2013. The Rigidity Trap. in Global Resilience: Neoliberalisation through Principles, Standards, and Benchmarks, Globalizations 10, no. 3 (2013): 383-95.

[56] Elizabeth B-N Sanders and Pieter Jan Stappers. 2008. Co-creation and the new landscapes of design. Co-design 4, 1: 5-18.

[57] Robert Soden, Perrine Hamel, David Lallemant, and James Pierce. 2020. The Disaster and Climate Change Artathon: Staging Art/Science Collaborations in Crisis Informatics. In Proceedings of the 2020 ACM Designing Interactive Systems Conference, 1273-1286.

[58] Cassie Thornton. 2020. The Hologram: Feminist, Peer-to-Peer Health for a PostPandemic Future. Pluto Press. ISBN: 9780745343327

[59] Josefin Wangel, Mia Hesselgren, Elina Eriksson, Loove Broms, Gabriel Kanulf, and Andrejs Ljunggren. 2019. Vitiden: Transforming a policy-orienting scenario to a practice-oriented energy fiction. Futures 112: 102440.

[60] Danielle Wilde. 2020. Design research education and global concerns. She Ji: The Journal of Design, Economics, and Innovation 6, 2: 170-212.

[61] Danielle Wilde*, Marketa Dolejšová, Sjef van Gaalen, Ferran Altarriba Bertran, Hilary Davis \& Paul G. Raven. (2021). Troubling the Impact of Food Future Imaginaries. Proceedings of the 2021 Nordic Design Research Conference (NORDES). *co-first authors

[62] Danielle Wilde, Anna Vallgårda, and Oscar Tomico. 2017. Embodied design ideation methods: analysing the power of estrangement. 5158-5170. https: //doi.org/10.1145/3025453.3025873

[63] Walter Willett, Johan Rockström, Brent Loken, Marco Springmann, Tim Lang, Sonja Vermeulen, Tara Garnett, David Tilman, Fabrice DeClerck, and Amanda Wood. 2019. Food in the Anthropocene: the EAT-Lancet Commission on healthy diets from sustainable food systems. The Lancet 393, 10170: 447-492.

[64] World Economic Forum. 2021. The Global Risks Report 2021, 16th Edition. ISBN: 978-2-940631-24-7. Retrieved February 17, 2021 from http://www3.weforum.org/ docs/WEF_The_Global_Risks_Report_2021.pdf 